\title{
Ethics and Responsibility of Scientific Researchers in a Pandemic Era
}

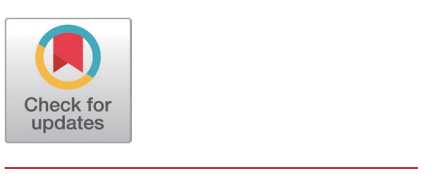

Received: August 17, 2021

Revised: October 27, 2021

Accepted: November 16, 2021

${ }^{+}$Corresponding author Kyung-Hee Lee

Dept. of Ethics Education, Sungshin

Women's University, Seoul 01133, Korea.

Tel: +82-2-920-7629

Fax: +82-2-920-7226

E-mail: leekh64@sungshin.ac.kr

Copyright @ 2021 The Korean Society of Developmental Biology.

This is an Open Access article distributed under the terms of the Creative Commons Attribution Non-Commercial License (http://creativecommons.org/licenses/ by-nc/4.0/) which permits unrestricted non-commercial use, distribution, and reproduction in any medium, provided the original work is properly cited.

ORCID

Kyunghee Lee

https://orcid.org/0000-0002-8504-3653

Conflict of interests

The authors declare no potential conflict of interest.

Acknowledgements I would like to thank the president and editorial director for giving me the opportunity to publish the manuscript in your prestigious journal.

Authors' contributions

The article is prepared by single author.

Ethics approval

This article does not require IRB/IACUC approval because there are no human and animal participants.
${ }^{\dagger}$ Kyung-Hee Lee

Dept. of Ethics Education, Sungshin Women's University, Seoul 01133, Korea

\section{Abstract}

The purpose of this paper is to critique the links between science and scientific researchers, politics and capital surrounding vaccines and vaccination in a pandemic era. It also introduces standards for adapting ethical guidelines for research under public health emergencies to specific circumstances and contexts. It also introduces ethical standards to be applied to scientific research. that is, scientific relevance, social value, cooperative partnerships, reasonable risk-benefit costs, fair and voluntary participation, independent review, and equal moral respect for participants and affected communities. It also outlines the COVID-19 (coronavirus disease 2019) pandemic-consent and other research procedure modifications proposed by Oregon Health and Science University (OHSU). We are on the lookout for powerful capital and hegemonic groups inseparable from politics and important decision makers in the pandemic era - that is, scientists, supporters, and scientific civic groups. It underscores the need for an independent and formal scientific advisory body with the right balance between science and politics.

Keywords: Pandemic, Scientific researcher, Ethics and responsibility, Vaccines, Science and politics, Public health, Emergencies

\section{INTRODUCTION}

In the winter of 2019, there was an outbreak of COVID-19(coronavirus disease 2019) in Wuhan, China. The world has entered a pandemic era and everything in the world is changing rapidly. The present era is said to be an era in which everything changes rapidly, is unpredictable, paradoxical, and intricately tangled. And it is said to be an era of volatility and uncertainty, complexity, and ambiguity.

The pandemic era has suddenly changed everything in the world. As COVID-19 has spread worldwide, as of November 30, 2021, there are 270 million confirmed cases and 5.3 million deaths. In order to prevent the spread of COVID-19, movement and travel between countries and regions has been banned, schools have switched to a non-face-to-face online system, and workplaces have switched to telecommuting, and vaccination is mandatory in most countries. Personal information (residence, contact information) and biometric information (face, iris, fingerprint, vein, etc.) are publicly disclosed for access to cafes, restaurants, public institutions, etc. and for public health.

In particular, personal information was leaked due to technologies using the human 'body' as coordinates. As a result, data about human rights issues emerged. However, people are getting used to surveillance and control. China is collecting biometric information of ethnic minorities in the Xinjiang Uyghur Autonomous Region without permission. In addition, through the Tenwang Project, a densely 
constructed internet network in the sky, it is able to distinguish the faces, eyes, and gait of the Chinese people. In the near future, a vaccine passport containing the history of people around the world infected with COVID-19 and vaccinated will become travel permits. In addition, DNA information of people around the world will be stored in the gene cloud and managed as a single system.

This paper will critique the implications of vaccines in a pandemic era and the link between the science and scientific researchers surrounding vaccines, and politics and capital. Additionally, it will introduce ethical standards for research in the context of consent issues, political public health emergencies, and COVID-19 research provided by Oregon Health and Science University (OHSU, 2020). I will also discuss the need for an independent and formal scientific advisory body with the right balance and the right tension between science and politics.

\section{THE MEANING OF A VACCINE IN THE PANDEMIC ERA}

Merriam Webster, a famous American dictionary publisher, selected 'Vaccine' as 'Word of the Year'. Following last year's pandemic, which referred to an infectious disease pandemic, the words related to COVID-19 were selected.

Merriam-Webster Publishing House announced that "vaccine is the word of the year because it is a major cause of political division and a promising medical solution." "Vaccines mean more than drugs," he said. However, it was also at the center of debate over personal choice, political affiliation, occupational regulation, and health care inequality." CNN evaluated it as "to some people it is a symbol of hope and health, and to others it is an expression of a political issue." (Lim, 2021; Kim, 2021).

According to The Guardian and The Times, a UK government advisory panel predicts that the new Omicron COVID-19 infection will continue to be a threat for at least five years and will require diagnostic testing and vaccination for another 10 years.

British senior scientist Jeremy Farrar, director of the Welcome Trust, criticized that the emergence of Omicron "shows that the pandemic is closer to the beginning than the end". And there were concerns that the progress made so far to overcome the pandemic could go in vain. "Governments are not addressing unequal access to vaccines, testing, and treatment, and this lack of political leadership is prolonging the pandemic," he twisted (Lee, 2021).

\section{COVID-19 VACCINATION: SCIENTIFIC DECISION VS. POLITICAL DECISION}

Why do countries and governments force people to get vaccinated without detailed explanation? Why aren't we teaching people how to naturally boost their immunity (vitamin $\mathrm{C}$, vitamin $\mathrm{D}$, sunshine, water, and aerobic exercise) to fight the virus?

The current vaccination controversy is clearly suspected to be 'vaccine politics'. Modern politics does not exist only as 'politics', but has to do with 'money' and 'capitalism', that is, hegemony. In other words, today's politics seems to operate in a way that maximizes profits through human body.

Jeong of Johns Hopkins University says that 'vaccine is science' but 'vaccination is politics' (Jung, 2021). Since last year, a team led by Northwestern University political psychologist James Druckman has been conducting 'The COVID-19 States Project', the largest in the United States. Survey results showed little change in overall public vaccination decisions observed in three cases: 
before discontinuation (70\%), while discontinuation was discussed (69\%), and after discontinuation was decided (70\%). The decision to discontinue did not increase vaccine hesitation or resistance.

In other words, there are two views regarding the fact that 'no clear causal relationship has been identified'. First, the public is already aware of the uncertainty of science. They just want to know how reliable the scientific findings presented are. Second, avoidance or reduction of uncertainty creates a false belief that an uncertain fact is certain. This may make it more difficult to accept new evidence or discoveries presented later, and trust in science may decline further in the process.

Of course, the politicization of vaccines is something to be wary of and confront. However, it is not scientific to exclude vaccination from such a situation closely related to partisanship.

\section{COUNTRIES WITH LOW COVID-19 VACCINATIONS: AFRICA AND GERMANY}

Why did the COVID-19 mutant virus, Omicron, originate in South Africa? It can be found in low vaccination rates. Africans have great distrust of vaccines. In the early 1900s, Germany conducted horrific human experiments on the inhabitants of Namibia. Most Africans have a strong objection to medicines due to their experiences in human experiments with smallpox, typhus, and tuberculosis injections.

In the late 20th century, global pharmaceutical companies such as Pfizer conducted clinical trials on African children without parental consent during the development of new drugs. During a clinical trial, there was a case in which children were killed as a result of side effects, and compensation was paid to parents. Also, when the AIDS epidemic in Africa killed millions of people, global pharmaceutical companies continued to sell the drug at a higher price without lowering the price. Violence by global pharmaceutical companies appears to be the current phenomenon of refusal of vaccines in Africa. After all, Africa became the birthplace of the COVID-19 strain (Kwon, 2021).

Jeong says recently, European German-speaking countries have the lowest number of COVID-19 vaccinations. Greece (63\%), Austria (65\%), Switzerland (65\%), and Germany (68\%) have the lowest vaccination rates in major European countries excluding Eastern Europe. Why? There are several common trends behind the low vaccination rates in the German-speaking world. This is because of the long-standing distrust of the central government, alternative education and medicine, and the expansion of the far-right party's power.

Sociologist Oliver Nachtwey of the University of Basel in Switzerland explained in an interview with a German newspaper Der Standard. The main characteristic shared by German-speaking countries such as Austria, Switzerland, and Germany is that the central government has weak power as it is a federal system. Therefore, there are many people who oppose the unified public education. Waldorf Alternative Education, first established in southern Germany in 1919 by Austrian thinker Rudolf Steiner, is a representative example. Currently, there are 236 such schools in Germany, 32 in Switzerland, and 21 in Austria. "About a quarter of all Waldorf schools in Germany are concentrated in the region with the lowest vaccination rates in Germany," Nachtwey said. He also pointed out that the Waldorf ideology, which emphasizes 'awareness' and 'the right to make decisions about the body, is connected with the view of vaccination as a violation of individual autonomy by the state' (Kim, 2021). 


\section{ETHICAL STANDARDS AND APPLICATION FOR RESEARCH DURING PUBLIC HEALTH EMERGENCY}

This ethical standard is not a 'full explanation' but selected from existing guidelines to support COVID-19 R\&D (CRE, 2020a). In all cases, including emergencies, our duty is to comply with internationally recognized ethical standards. However, these universal ethical standards can be tailored to specific situations and contexts. Ethical standards that research must meet in this context are scientific relevance, social value, collaborative partnerships, reasonable risk-benefit costs, fair and voluntary participation, independent review, and equal moral respect for participants and affected communities (CRE, 2020b).

Ethical guidelines and applications for research in public health emergencies are as follows.

- Research should only be conducted if it does not interfere with emergency response efforts.

- What should a collaborative research partnership look like in an emergency?

- How should the community be involved in research activities?

- Matters that require independent ethical review and how should such review be conducted in an emergency?

- Can the research methodology be applied in case of emergency?

- How should research participants be selected and recruited in case of emergency?

- What are the prior consent requirements in an emergency?

- To what extent should research data and samples be shared in case of emergency?

- How should research interests be shared in case of emergency?

\section{COVID-19 PANDEMIC - MODIFYING CONSENT AND OTHER STUDY PROCEDURES}

OHSU has summarized the COVID-19 Pandemic - Modifying consent and other study procedures as follows:

1. For more information on OHSU (2020) research policies and resources related to the COVID-19 pandemic, visit the OHSU O2 COVID-19 Research page.

2. Investigators must review the study protocol and include changes from study visits that do not need to be conducted on-site to remote visits and will require eIRB (electronic institutional review board) submission.

Research protocol modifications should include sponsor monitoring visits, site selection/ initial visits, and non-visiting research activities (data analysis, manuscript preparation, grant proposal preparation, and protocol preparation and submission).

3. If there is no time to obtain IRB approval for a change necessary to comply with infection control measures, it is considered a 'change to prevent imminent harm'.

4. To safely consent to research subjects during the COVID-19 pandemic, remote research visits should be conducted to protect subjects and research teams and prevent the spread of COVID-19 to other communities. However, if there are difficulties in obtaining consent, the protocol should be modified. In particular, obtaining consent may involve unbiased witnesses (persons separate from the research team) both indoors and by telephone consent. A legally valid electronic consent is established in the consent document.

5. It was determined that the conduct of the study that did not require IRB approval did not require protocol changes. 


\section{DECISION-MAKERS IN SCIENTIFIC RESEARCH: SCIENTIST VS. SPONSOR VS. SCIENTIFIC CIVIC ORGANIZATION}

"Who makes decisions in scientific research?" After the development of modern science, scientific research by scientists was possible only because of the sponsors who supported them. It is true that scientists have been limited in their independence and autonomy (Lee, 2013). In particular, with the advent of mega-science and mega-science policies, superpowers and multinational corporations have paid huge amounts of money to hire scientists. Can you oppose the decision of the person giving the money?

In this journal, I have appealed to problems arising in the relationship between science and scientists, capital and business, politics, and power, focusing on the unjust alliance between university-business and non-profit-profit. Also, I have pointed out the problems of commercialization of science, commercialization of universities, and contract science. In order to solve this problem, it is necessary to pay attention to public interest science and sound science, which are the opposite concepts of contract science, and undone science, which is a new integrated point of view.

In addition, it is very meaningful to study scientific freedom, open science, popularization of science and scientificization of the masses, and citizen democracy and scientific democracy as alternative concepts (Lee, 2017).

The right tension and the right balance between science and politics are required. In other words, an independent and formal scientific advisory body is needed. The case of the UK's Scientific Advisory Group for Emergencies offers some insights in this regard. The Advisory Group is the scientific advisory body of the UK Government Emergency Response Room chaired by the Prime Minister.

The advisory group consists of a diverse group of experts, including epidemiologists, clinicians, vaccine experts, public health experts, virologists, environmental scientists, data scientists, mathematical modeling experts, genomic experts, behavior experts, and sociologists. They consider various social values and situations, draw a final conclusion through deliberation and discussion, and the decision-making body is responsible for all decisions.

It is important to strike a balance that makes the most of the strengths of science and politics, but creates tension between the two. If there is an official advisory body that is functionally independent but placed under a major decision-making body, at least there will be no misunderstandings such as 'secret advisory group', 'vaccine politics', and 'political quarantine'(Jung, 2021).

Eliot Friedson says, "The most important problem for future professionalism is not economic or structural, but cultural and ideological" (Freidson, 2001; Lee, 2013). In other words, the spirit required of scientific researchers is professionalism, not economics.

\section{DISCUSSION}

In this pandemic era, where everything is rapidly changing, we need to think about how to educate scientific researchers. Education that guarantees human dignity and autonomy, education that criticizes and reflects, education that thinks, judges, decides, and takes responsibility for oneself, education that develops insight through the times, interdisciplinary convergence education that integrates humanities and social sciences, problem-solving type project education, education to solve the pain and anxiety of the contemporary human race, community-connected education, and empathy education are urgently needed. 


\section{REFERENCES}

Center for Research Ethics Information [CRE] (2020a) COVID-19 pandemic: Modifications to consent and other research procedures. Available from: https://www.cre.or.kr/bbs/BoardDetail. do?nttId=479\&bbsId=BBSMSTR_000000000067\&pageIndex=1. Access at Nov 30, 2021.

Center for Research Ethics Information [CRE] (2020b) Ethical standards for research during public health emergencies. Available from: https://www.cre.or.kr/bbs/BoardDetail. do?nttId=89\&bbsId=BBSMSTR_000000000054\&pageIndex=1. Access at Nov 30, 2021.

Freidson E (2001) Professionalism: The third logic. University of Chicago Press, Chicago, IL, pp $111-156$.

Jung WG (2021) Why 'vaccine is science' but 'vaccination' is not science. Sisain. Available from: https://www.sisain.co.kr/news/articleView.html?idxno=44760. Access at Dec 7, 2021.

Kim JK (2021) Why are German-speaking countries so low in vaccination rates? Sisain. Available from: https://www.sisain.co.kr/news/articleView.html?idxno=46150. Access at Dec 11, 2021.

Kim JW (2021) Merriam-Webster, a US dictionary company, named 'vaccine' as 'word of the year'. Hankookilbo. Available from: https://www.hankookilbo.com/News/Read/ A2021113011150000176?did=DA. Access at Nov 30, 2021.

Kwon MC (2021) A biological experiment nightmare... Why Omicron is rooted in Africa. Nocutnews. Available from: https://www.nocutnews.co.kr/news/5666904. Access at Dec 2, 2021.

Lee HK (2021) "Corona lasts at least 5 more years"... I have a gloomy prospect. Korea Economic TV. Available from: https://n.news.naver.com/mnews/article/215/0001001715?sid=104. Access at Dec 5, 2021.

Lee KH (2013) Conflict of interest in scientific study and bioethics as professionalism. Dev Reprod 17:477-482.

Lee KH (2017) Science and politics, ethics of scientist. Journal of Ethics. 113:135-157.

Lim SS (2021) Merriam-Webster's word of the year is 'vaccine'... "The cause of political division and the medical solution”. Kukminilbo. Available from: http://news.kmib.co.kr/article/view. asp?arcid $=0016521202 \&$ code $=61131111 \& c p=d u$. Access at Nov 30, 2021.

Oregon Health and Science University [OHSU] (2020) COVID-19 Pandemic - Modifying consent and other study procedures. Available from https://www.ohsu.edu/research-integrity/ irb-frequently-asked-questions-faqs. Access at Nov 30, 2021. 